\title{
The efficiency of walking of paraplegic patients using a reciprocating gait orthosis
}

\author{
M Bernardi ${ }^{1}$, I Canale ${ }^{2}$, V Castellano ${ }^{2}$, L Di Filippo $^{1}$, F Felici $^{1}$ and M Marchetti ${ }^{1}$ \\ ${ }^{1}$ Istituto di Fisiologia Umana, Facoltà di Medicina, Università di Roma 'La Sapienza', Piazzale Aldo Moro 5, \\ 1-00185 Roma; ${ }^{2}$ Instituto di Ricovero e Cura a Carattere Scientifico Clinica S. Lucia, Roma, Italy
}

\begin{abstract}
A number of orthoses have been designed to restore stance and walking in paraplegic subjects. Among them, the reciprocating gait orthosis (RGO) appears to be one which is most widely adopted. The great energetic cost of orthotically aided walking is the main factor limiting the walking capability of paraplegic subjects. The purpose of the present research was to give a complete biomechanical evaluation of RGO locomotion in order to provide data that can be used for further improvements of the orthosis. From the whole body kinematics the mechanical work done to move the orthosis was estimated; by measuring the actual metabolic cost of RGO locomotion the efficiency was evaluated as the ratio between mechanical work and energy expenditure. It is found that RGO locomotion is a very demanding task in terms both of energy expenditure and of the mechanical work required. Furthermore, it is evident that the major determinant of this poor efficiency of RGO locomotion is the enormous amount of work required to move the orthosis which, in turn, reflects its poor mechanical characteristics. To accomplish the demand of real mobility, devices for transferring work from the upper to the lower portion of the body must be substantially improved. This technical aspect must be parelleled by suitable training programmes especially designed to improve the aerobic power of paraplegic subjects and their body composition (ie less fat and more muscle).
\end{abstract}

Keywords: paraplegic subjects; locomotion; efficiency; reciprocating gait orthosis

\section{Introduction}

Among the systems designed to restore stance and walking in paraplegic patients, the reciprocating gait orthosis ${ }^{1}$ seems to be the most widely adopted. ${ }^{2}$ In Italy the RGO was introduced only 2 years ago, and its diffusion in the paraplegic population is steadily increasing. An ad hoc inquiry performed among our patients revealed that the great majority of them use the RGO only at home, for $1-2 \mathrm{~h}$ a day. In consideration of the benefits which ambulation can promote for paraplegic life style and general health, it seems useful to investigate the reasons for this very limited use. The great energy cost of orthotic walking has been extensively reviewed ${ }^{3-5}$ and from these studies it emerges that the walking capability of a paraplegic subject depends on the fraction of maximum aerobic power requested to move each orthosis being considered. From the beginning of its history, the RGO device has been integrated with functional electrical stimulation (FES) of lower limb musculature. ${ }^{6}$ The idea was that FES would improve RGO walking, both in terms of speed of progression and metabolic cost, thus improving the efficiency of the performance. Nevertheless, to our knowledge, this hypothesis has been scarcely tested.

Correspondence: Prof. Marco Marchetti
From our inquiry it emerges that the integration with FES is generally rejected as a tedious procedure of scarce efficacy, and, at least in our sample, the RGO is used as a purely passive orthosis. While a great amount of data has been collected on the metabolic energy requirements, few data are available on the biomechanics of RGO walking. Ferrarin et $a l^{7}$ evaluated the stiffness of the Orlau Parawalker (The Robert Jones and Agnes Hunt Orthopaedic Hospital, Oswestry, United Kingdom) in order to provide valuable information for the improvement of orthosis design; Jefferson and Whittle compared three different types of orthoses. ${ }^{8}$ It is evident that any attempt to improve RGO walking must be based on the knowledge of the kinematics and dynamics of body segments during RGO locomotion. The present research was aimed at the biomechanical evaluation of RGO locomotion without FES. This was accomplished by (1) measuring the whole body kinematics and evaluating the total mechanical work done (whole body potential and kinetic energy changes); (2) measuring the actual cost of $\mathrm{RGO}$ gait (metabolic energy expenditure) in a representative population of paraplegic individuals; and (3) evaluating the efficiency in terms of a ratio between total mechanical work done and energy expenditure. 


\section{Material and methods}

The study was performed on 10 paraplegic subjects and seven normals. Their relevant anthropometric characteristics are provided in Table 1 . The paraplegic patients had a traumatic section of the spinal cord at various thoracic levels (from T4 to T12). They all wore an RGO orthosis (LSU-RGO model ${ }^{6}$ Rizzoli Factory, Bologna, Italy) and were all well trained in its use. All the subjects gave their informed consent to the research. The oxygen uptake $\left(\dot{\mathrm{VO}}_{2}\right)$ was measured both while standing and during ambulation at natural speed, ie the speed selected by the subject as the most comfortable. In the case of the normal subjects, three additional speeds were requested, which the subject selected as fast, slow and very slow, this latter being requested to simulate the very slow speed of paraplegic people. The exercise was performed by having the subject walk along a flat indoor walkway $25 \mathrm{~m}$ long, until a condition of steady state was reached. At the end of the walkway the subject turned around and walked back in the opposite direction. The walkpath was marked at intervals of $5 \mathrm{~m}$; by noting the time spent walking to each mark, an average walking speed was obtained. A telemetering apparatus (K2, Cosmed) was used for the $\dot{\mathrm{VO}}_{2}$ measurements. This device, as is described in detail elsewhere,${ }^{9}$ is very light $(700 \mathrm{~g})$, and does not interfere with the motor ability of the subjects. The data were continuously sampled (every $30 \mathrm{~s}$ ). Steady state values were recorded for $5 \mathrm{~min}$; the distance covered during the $5 \mathrm{~min}$ of steady state condition differed among RGO subjects due to their different mean speed of progression, ranging between 25 and $100 \mathrm{~m}$. At the end of each session, the entire experiment record was stored on a PC (Olivetti M380 XP9) for further analysis.

The peak aerobic power was measured in four paraplegic subjects using an arm crank ergometer (Fleish, Jacquet SA, Switzerland), and following a test protocol previously designed by us for the characterisation of paraplegic athletes. ${ }^{10}$ Arm cranking frequency was fixed at 60 rounds per minute and the load was increased stepwise by 25 watts every 2 min until exhaustion. $\dot{\mathrm{VO}}_{2}, \dot{\mathrm{V}} \mathrm{CO}_{2}$, and $\dot{\mathrm{V}} \mathrm{E}$ were measured by means of an automatic gas analyser EOS Sprint, Jaeger, Germany. From these data ventilatory threshold was estimated.

The mechanical work done during a whole gait cycle was evaluated in four paraplegic subjects and in two normal subjects by considering the potential and kinetic energy changes associated with each body segment. The following body segments were considered: (1) head, (2) arm, (3) forearm, (4) trunk, (5) thigh, (6) shank and (7) foot. The above body segments were identified by placing infrared light emitting diods on the following relevant anatomical landmarks: the centre of the zygomatic process; below the acromion on the lateral aspect of the shoulder; the epitroclear process of the humerus; the styloid process of the ulna; the midline of the lateral aspect of the neck at $\mathrm{C} 4$ level; the greater trochanter (the mechanical hip joint of RGO device in the case of those who were paraplegic); the centre of the knee; the lateral malleolus; the heel and ball of the foot. Tridimensional kinematics of each segment were obtained by means of an optoelectronic device (Costel, LogIn, Italy). The masses of the segments, the location of their centres of gravity, and the moments of inertia were obtained from the Zatziorsky and Seluyanov tables. ${ }^{11}$ For each segment, the potential energy was calculated as the vertical displacement of the centre of gravity times the segment weight. Kinetic energy was calculated as:

$$
E_{k j}=1 / 2 m_{j} v_{j}^{2}+1 / 2 m_{j} k_{j}^{2} \omega_{j}^{2}
$$

where $m_{j}$ is the mass of the $j$ segment, $v_{j}$ is its linear velocity, $k_{j}$ is the radius of gyration, and $\omega_{j}$ is the angular velocity.

\section{Statistical analysis}

While standing and during ambulation only $\dot{\mathrm{VO}}_{2}$ data at steady state were taken into account. Metabolic energy expenditure while standing and during ambulation was computed as follows:

$$
E=k \cdot\left(\dot{\mathrm{V}}_{2}\right)
$$

where $\mathrm{V}_{2}$ is the oxygen cost (in $\mathrm{ml} \mathrm{s}^{-1} \mathrm{~kg}^{-1}$ ) and $k$ is the energy $(\mathrm{J})$ equivalent of oxygen. Thus $E$ assumes the units of $\mathrm{J} \mathrm{kg}^{-1} \mathrm{~s}^{-1}$.

All patients' data were considered as linearly dependent on the walking velocity: therefore, a regression analysis was carried out in order to evaluate (1) the intercept and the slope of the regression line and their standard deviations; (2) the linearity of the regression; (3) the significance of the regression coefficient against zero; (4) the significance of the difference between regressions (ie between different subjects). In normal subjects the simple linear regression failed to fit the data, thus a polynomial equation was introduced. Classic statistical test procedures were adopted. ${ }^{12}$ Finally, cumulative regressions for normals and RGO patients were obtained and compared.

Based on Paul's suggestion, ${ }^{13}$ a physiological cost

Table 1 Anthropometric characteristics of subjects (mean values \pm SD)

\begin{tabular}{lcccccc}
\hline & Sex & $N$ & $\begin{array}{c}\text { Age } \\
\text { (years) }\end{array}$ & $\begin{array}{c}\text { Stature } \\
(\mathrm{cm})\end{array}$ & $\begin{array}{c}\text { Mass } \\
(\mathrm{kg})\end{array}$ & $\begin{array}{c}\text { Lesion level } \\
(\text { range })\end{array}$ \\
\hline Group A RGO & $\mathrm{F}$ & 4 & $36 \pm 11$ & $162 \pm 5$ & $57 \pm 9$ & $\mathrm{~T} 4-9$ \\
& $\mathrm{M}$ & 6 & $23 \pm 4$ & $175 \pm 9$ & $67 \pm 11$ & $\mathrm{~T} 5-12$ \\
Group B Normals & $\mathrm{F}$ & 3 & $26 \pm 3$ & $167 \pm 4$ & $60 \pm 7$ & \\
& $\mathrm{M}$ & 4 & $32 \pm 13$ & $177 \pm 6$ & $75 \pm 9$ & \\
\hline
\end{tabular}


index was calculated according to the following formula:

$$
E P C I=\left(E_{W}-E_{S T}\right) / v
$$

where $E_{S T}$ is the energy expenditure during standing, $E_{W}$ is the energy expenditure during walking, $v$ is the walking speed in $\mathrm{m} \mathrm{s}^{-1}$ and, thus, EPCI is the net energy physiological cost index per unit of body mass and distance $\left(\mathrm{J} \mathrm{kg}^{-1} \mathrm{~m}^{-1}\right)$.

Differences in walking mechanical power between RGO subjects and normal subjects were evaluated adopting the same statistical procedures as above. Quadratic regression curves were used to fit the data.

\section{Results}

In Table 2 the peak $\mathrm{VO}_{2}$ values measured in four $\mathrm{RGO}$ subjects during the ergometric test are given; in the same table, the mean walking speed and the corresponding $\dot{\mathrm{V}}_{2}$ values obtained during the walking test are reported as absolute values and as ratio of the peak values for the same subjects.

The relationship between metabolic energy expenditure and speed of progression is reported in Figure 1. In contrast to normal subjects, those who were paraplegic have a very limited range of velocity, and therefore only one value for each subject - the natural velocitywas considered in this group. In all of the paraplegic patients all levels of attainable velocity were well below the values referred to as 'slow' by the normal subjects. In Figure 1 the linear correlation for paraplegic subjects is reported and the equation is shown in the legend. An $\mathrm{F}$ test demonstrated that in normal subjects the regression was non-linear, especially when very low speeds were considered. The typical S-shaped curve, that we calculated in accordance with Margaria, ${ }^{14}$ provided the best fit for our data. It is evident that walking at the same speed was more demanding in RGO subjects than in the normal subjects.

In Table 3 the EPCI and $E_{W}$ are compared between RGO patients and normal subjects walking at low and very low speed. Since authors (Table 4) who have measured energy cost of walking for those who are paraplegic referred it as gross walking cost without subtracting $\mathrm{VO}_{2 \text { st }}$, in table 4 gross EPCI values obtained in the present study are also reported. The difference between RGO subjects and normals is highly significant $(P<0.05)$ in all instances.

An example of kinetic and potential energy changes

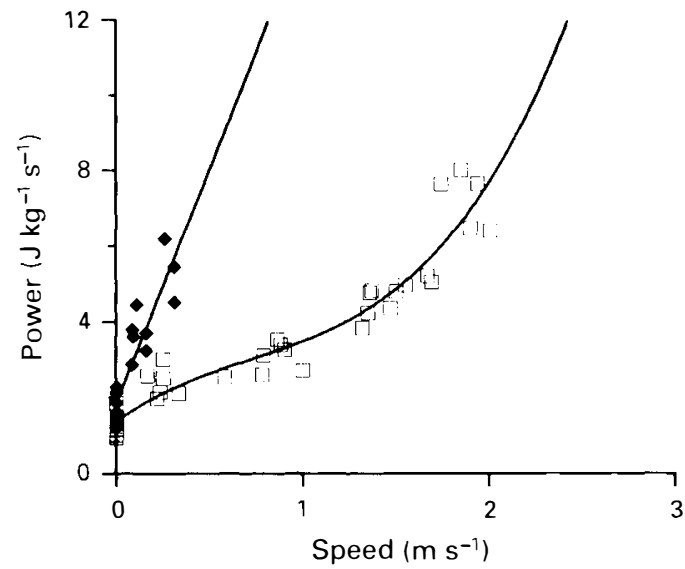

Figure 1 Relationship between metabolic energy expenditure and speed of progression. Filled symbols: RGO; open symbols: normal subjects. RGO: $y=1.9+12.4 x\left(\mathrm{R}^{2}=\right.$ $0.93)$; Normals: $y=1.4+3.6 x-2.7 x^{2}+1.2 x^{3}\left(\mathrm{R}^{2}=0.81\right)$

is shown in Figure 2, as the total energy variation, ie the sum of energy changes in each segment $(j)$ in any given time sample $(t)$

$$
E_{k t o t}(t)=\sum_{j=1}^{n} E_{k j}(t) ; \quad E_{p t o t}(t)=\sum_{j=1}^{n} E_{p j}(t)
$$

where $E_{k j}(t)$ is the kinetic energy (translational) of the $j$ th segment at time $t$ and $E_{p j}(t)$ its potential energy at same time. This figure shows a comparison between a paraplegic subject walking with an RGO and a normal subject walking approximately at the same speed. In Figure 2, the kinetic and potential energy curves are also shown. The greater RGO mechanical work with respect to a normal is due to: (1) the greater relevance of kinetic energy contribution; (2) the inphase variation of kinetic and potential energy. The inphase behaviour is a walking feature common to all RGO subjects. In the same Figure 2 the energy variations of the upper portion of the body during walking are also reported for both RGO and normal subjects. The major contribution of lower limb kinetic energy to the total energy variation is evident.

The mean mechanical power produced during walking is represented in Figure $3 \mathrm{a}$ as a function of the walking speed for both normal and paraplegic subjects. This power was calculated, in accordance with Ralston and Lukin, ${ }^{18}$ as the sum of each positive increment of

Table 2 Comparison between $\dot{\mathrm{V}} \mathrm{O}_{2}$ uptake of $\mathrm{RGO}$ subjects while standing and walking versus peak $\dot{\mathrm{V}} \mathrm{O}_{2}$ measured during maximal ergometric test. In addition, speed of progression and $\dot{\mathrm{V}} \mathrm{O}_{2}$ at threshold are also reported

\begin{tabular}{lcccccc}
\hline Subject & $\begin{array}{c}R G O \text { standing } \dot{\mathrm{V}} \mathrm{O}_{2} \\
\left(\text { lmin }^{-1}\right)\end{array}$ & $\begin{array}{c}\text { RGO walking } \dot{\mathrm{V}} \mathrm{O}_{2} \\
\left(\text { (min }^{-1}\right)\end{array}$ & $\begin{array}{c}\text { Speed } \\
\left(\mathrm{m} \mathrm{min}^{-1}\right)\end{array}$ & $\begin{array}{c}\text { Ergometry } \dot{\mathrm{V}} \mathrm{O}_{2} \text { peak } \\
\left(\text { (min }^{-1}\right)\end{array}$ & $\begin{array}{c}\text { Ergometry } \dot{\mathrm{V}} \mathrm{O}_{2} \text { trh } \\
\left(\text { ( min }^{-1}\right)\end{array}$ & $\begin{array}{c}\text { Walking vs } \\
\text { ergometry }\end{array}$ \\
\hline 1 & $0.29 \pm 0.12$ & $0.63 \pm 0.04$ & $9.6 \pm 2.4$ & $0.86 \pm 0.08$ & $0.72(83 \%)$ & $73 \%$ \\
2 & $0.34 \pm 0.03$ & $0.43 \pm 0.07$ & $4.5 \pm 1.02$ & $0.85 \pm 0.07$ & $0.75(88 \%)$ & $50 \%$ \\
3 & $0.38 \pm 0.04$ & $0.81 \pm 0.05$ & $19.4 \pm 0.9$ & $1.27 \pm 0.07$ & $0.9(70 \%)$ & $63 \%$ \\
4 & $0.26 \pm 0.02$ & $0.72 \pm 0.04$ & $9.6 \pm 3$ & $1.38 \pm 0.05$ & $1.06(76 \%)$ & $52 \%$ \\
\hline
\end{tabular}


Table 3 Comparison between walking energy expenditure and walking cost in RGO and normal subjects (mean values $\pm \mathrm{SD})$

\begin{tabular}{lcccccc}
\hline Group & $\begin{array}{c}\text { Number of } \\
\text { subjects }\end{array}$ & $\begin{array}{c}E_{S T^{a}} \\
\left(\mathrm{Jkg}^{-1} \mathrm{~s}^{-1}\right)\end{array}$ & $\begin{array}{c}E_{W^{b}} \\
\left(\mathrm{Jkg}^{-1} \mathrm{~s}^{-1}\right)\end{array}$ & $\begin{array}{c}\text { Gross EPCI } \\
\left(\mathrm{Jkg}^{-1} \mathrm{~m}^{-1}\right)\end{array}$ & $\begin{array}{c}\text { EPCI } \\
\left(\mathrm{Jkg} \mathrm{kP}^{-1} \mathrm{~m}^{-1}\right)\end{array}$ & $\begin{array}{c}\text { Speed } \\
\left(\mathrm{ms}^{-1}\right)\end{array}$ \\
\hline RGO & 10 & $1.83 \pm 0.36$ & $4.47 \pm 1.24$ & $20 \pm 8$ & $11 \pm 4$ & $0.26 \pm 0.16$ \\
Normals very low speed & 6 & $1.5 \pm 0.32$ & $2.38 \pm 0.39$ & $10.34 \pm 3.09$ & $3.76 \pm 1.66$ & $0.24 \pm 0.05$ \\
Normals low speed & 7 & $1.1 \pm 0.14$ & $3.02 \pm 0.41$ & $3.71 \pm 0.56$ & $2.35 \pm 0.45$ & $0.82 \pm 0.13$ \\
\hline
\end{tabular}

${ }^{a}$ Energy expenditure during standing

${ }^{b}$ Energy expenditure during walking

${ }^{c}$ Gross energy physiological cost index per unit of body mass and distance

dNet energy physiological cost index per unit of body mass and distance (see Equation 1)

Table 4 Literature survey of walking energy expenditure measured by various authors in paraplegic subjects walking with different orthoses

\begin{tabular}{|c|c|c|c|c|c|}
\hline Series & Lesion level & Orthosis & $\begin{array}{l}\text { Speed } \\
\left(m s^{-1}\right)\end{array}$ & $\begin{array}{c}E_{W}{ }^{a} \\
\left(J k^{-1} S^{-1}\right)\end{array}$ & $\begin{array}{c}\text { Gross EPCI } \\
\left(\mathrm{J} \mathrm{kg}^{-1} \mathrm{~m}^{-1}\right)\end{array}$ \\
\hline Huang et al ${ }^{15}$ & $\mathrm{~T} 4$ & biKAFO & 0.178 & 3.60 & 18.16 \\
\hline \multirow[t]{2}{*}{ Clinkingbeard et al ${ }^{16}$} & $\mathrm{~T} 4$ & biKAFO & 0.070 & 2.58 & 35.92 \\
\hline & $\mathrm{T} 4$ & biKAFO & 0.040 & 1.87 & 44.80 \\
\hline Merkel et al ${ }^{17}$ & T6-9 & bissKAFO & 0.172 & 3.83 & 22.37 \\
\hline Nene and Patrick ${ }^{3}$ & T4-9 & ORLAU PW & 0.214 & 3.10 & 16 \\
\hline \multirow[t]{2}{*}{ Hirokawa et $a l^{4}$} & $\mathrm{~T} 1-10$ & RGO & 0.21 & 4.18 & 21 \\
\hline & & $\mathrm{RGO}+\mathrm{FES}$ & 0.21 & 4 & 18 \\
\hline \multirow[t]{2}{*}{ Puricelli et $a l^{5}$} & T10-L2 & VR & 0.12 & 3.27 & 34.85 \\
\hline & T3-10 & VR & 0.045 & 3.92 & 117.15 \\
\hline Present series & $\mathrm{T} 4-12$ & RGO & 0.213 & 4.3 & 20 \\
\hline
\end{tabular}

${ }^{a}$ Energy expenditure during walking

${ }^{b}$ Gross energy physiological cost index per unit of body mass and distance

VR = Vannini Rizzoli stabilizer

biKAFO = bilateral knee-ankle-foot orthosis

ORLAU PW = ORLAU Parawalker

bissKAFO = bilateral single stopped knee-ankle-foot orthosis

total energy during a double stride interval divided by the double stride duration $(T)$.

$$
P 1=T^{-1} \cdot \sum_{i=1}^{n} \Delta E_{i} .
$$

For normal subjects, the data we had obtained in previous research were considered ${ }^{19}$ in addition, further measurements were done during the present research on normals walking at the very low speed range typical for RGO subjects. Following Winter ${ }^{20}$ for both RGO subjects and normals (present series), the mean power was also calculated as the sum of absolute values of energy variations (see Figure $3 b$, dashed lines):

$$
P 2=T^{-1} \cdot \sum_{i=1}^{n}\left|\Delta E_{i}\right| .
$$

For both the normal and RGO groups, the quadratic regression curves, represented on the graphs, were adopted. Statistical analysis demonstrated that curves fit the experimental data, the difference between RGO patients and normals being statistically significant $(P<0.05)$. In Figure 3a, mean mechanical power calculated using $P 1$ equation is considered. In Figure $3 \mathrm{~b}$, the shaded area of Figure $3 \mathrm{a}$ is expanded and both $P 1$ and $P 2$ methods are considered. It is evident that both in normals and in RGO patients $P 2$ data almost doubled $P 1$ data.

In Table 5 the mean walking work done by each RGO subject is given. This work was calculated as the ratio between the total energy variation per second and the walking speed. Thus, it assumes the meaning of work per unit of walking length. Efficiency has been obtained as the ratio between walking work and net walking cost.

\section{Discussion}

\section{Energy cost of walking}

Our data on normal subjects agree with the data reported in the literature. ${ }^{14,21,22}$ Referring to RGO walkers, we have to distinguish two aspects, which reflect two ways of presenting the data. First, the cost of walking per unit of time, which is indicated by Nene and Patrick ${ }^{3}$ as energy consumption. These data allow a comparison with the maximum allowable rate of metabolic energy. The very high oxygen uptake per 


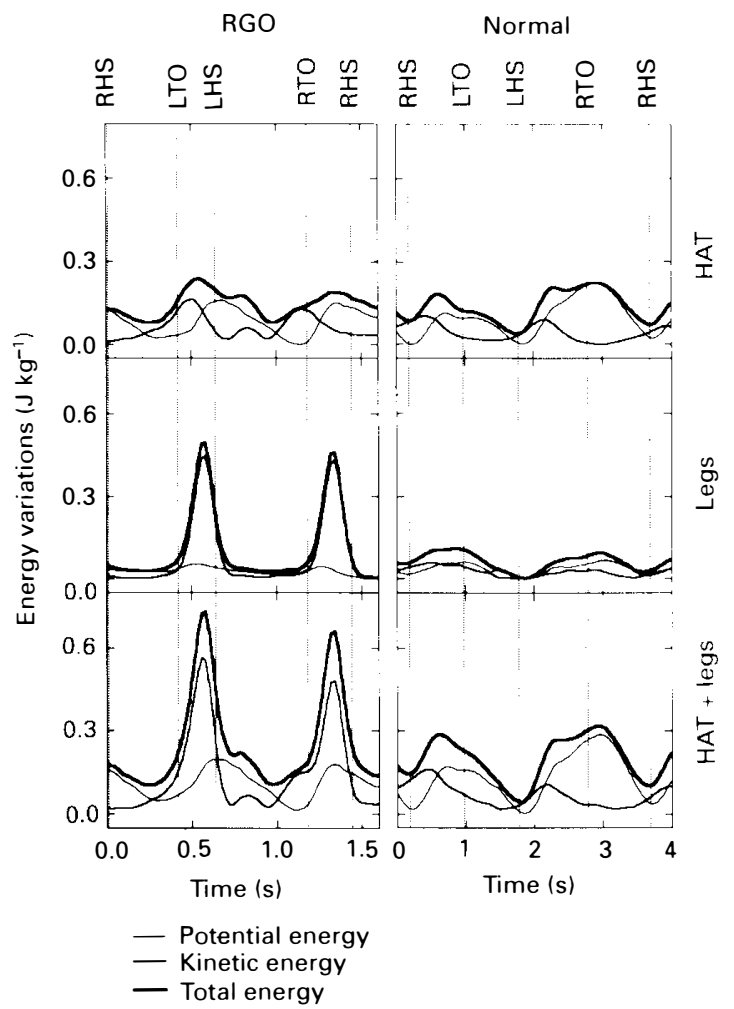

Figure 2 HAT (head, arm and trunk), legs (thigh, calf and foot of both legs) and HAT plus legs potential (thinner line), kinetic (thin line) and total (thick line) energy variations in RGO and normal subjects walking at approximately the same speed. It must be noted that at the same speed of progression, the normal subject has a stride length and a stride duration double that of a RGO subject. Thus this latter presents, for the same time interval, greater energy changes than the former in all body segments

minute in our paraplegic subjects using passive orthosis is consistent with literature data as shown in Table 4. The main problem is represented by the close proximity of this uptake to the maximum allowable to the subject as shown in Table 2. It can be questioned if the $\mathrm{VO}_{2}$ peak actually represents the maximum aerobic power of the subject. It may be stressed that the peak values we assumed were well above the anaerobic threshold values. Therefore, we can postulate that RGO walking is an exercise done at the limits of the onset of blood lactate accumulation (OBLA). Should the patient be requested to increase the speed, these limits will be exceeded and the exercise will become anaerobic, ie walking must be stopped every few steps. On the other hand, it is well known that paraplegic subjects have very reduced $\dot{\mathrm{VO}}_{2}$ peak values as a consequence of the reduced active muscle mass. In previous research, ${ }^{10}$ we obtained $1.61 \mathrm{~min}^{-1}$ as the mean $\dot{\mathrm{V}} \mathrm{O}_{2}$ peak value in wheelchair athletes of Olympic level, and sedentary paraplegic people are well below this level..$^{23,24}$

A different way of considering the metabolic energy expenditure is the unit cost of the walking per unit of distance. An implicit tenet of rehabilitation techniques is to approach normality as near as possible. In normal

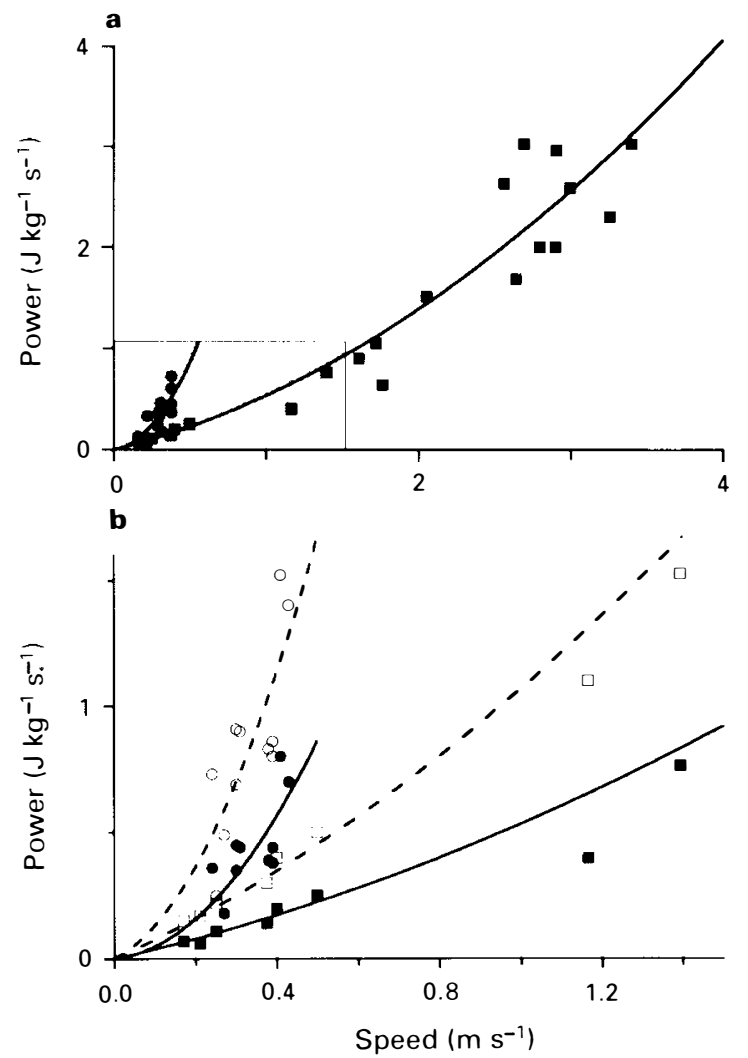

Figure 3 Mechanical power $v s$ walking speed for both normal (squares) and paraplegic subjects (circles). (a) Curves obtained using the Ralston and Lukin method. (b) The shaded area of (a) was expanded and curves obtained using Winter's method are also reported

Table 5 Mean walking work ( \pm SD) and efficiency for each RGO subject

\begin{tabular}{lccc}
\hline Subject & $\begin{array}{c}\text { Walking work } \\
\left(\mathrm{J} \mathrm{m}^{-1} \mathrm{~kg}^{-1}\right)\end{array}$ & $\begin{array}{c}\text { Walking speed } \\
\left(\mathrm{ms}^{-1}\right)\end{array}$ & $\begin{array}{c}\text { Efficiency } \\
(\%)\end{array}$ \\
\hline 5 & $1.075 \pm 0.09$ & 0.37 & 8.7 \\
6 & $1.23 \pm 0.29$ & 0.28 & 9.8 \\
7 & $1.40 \pm 0.42$ & 0.38 & 11.2 \\
8 & $0.57 \pm 0.16$ & 0.26 & 4.6 \\
\hline
\end{tabular}

locomotion, the cost for each unit of distance has been widely used as net cost. ${ }^{25}$ From this point of view, the RGO walking cost is more than twice that of any other form of locomotion in normal subjects, including running and competitive walking at maximum speed. Even when normal subjects are walking at the very low speed typical of RGO users, RGO walking cost is three to four times greater (Table 3). Furthermore, when it is also compared with locomotion cost of very handicapped (multiple sclerosis) persons, RGO walking is always twice as demanding. Judging from this normality criterion passive orthoses seem to be very poor rehabilitative devices. Our gross walking cost data, shown in Table 4 , are very close to those obtained by Hirokawa et al. ${ }^{4}$ As pointed out by these authors, it is 
evident that the new generation of orthoses presents a definite advantage with respect to other ambulation devices like biKAFO and VR ones.

A question may be raised at this point: is the RGO walking cost so high because of a very relevant mechanical work demand or because of the very poor metabolic efficiency, ie mechanical work $v s$ energy cost ratio?

\section{RGO mechanical work}

Errors in measuring mechanical quantities can only be evaluated from a theoretical point of view. We have considered the trunk as a rigid body; but actually, it changes in shape during each step, and markedly in RGOs. Considering that the great part of the deformation involves the shoulder system-ie clavicle plus scapula and soft tissues attached-we simulated this movement on a computer and thus estimated a $10 \%$ surplus to be added to the trunk total energy variation. Therefore, it seems likely that our RGO data underestimates actual energy variations, and the differences between normals and RGO subjects might be greater if a more accurate method in measuring body kinematics was available to us.

A major source of error arises from the choice of the filtering frequencies which mainly affect the computation of linear and rotational velocity, and thus, the calculation of kinetic energy variations. We used the Fourier series approximation with an upper harmonics limit chosen in accordance with the minimisation of the mean square error as indicated by Cappozzo et al ${ }^{26}$ The use of other filtering techniques, eg spline function, led to equivalent results, but still the choice of upper frequency cut off was critical.

The method we used in calculating the mechanical work during RGO ambulation is consistent with the studies performed on normal subjects, the difference among the authors depending on the assumptions made by the authors. Ralston and Lukin ${ }^{18}$ added only positive increments, while Winter ${ }^{20}$ added absolute values of both positive and negative increments. When only positive increments of mechanical energy are considered, it is assumed that muscular work is required only in this case being negative work done by external forces (vincular reaction forces and gravity force). By adding both postive and negative energy variations, it is assumed that negative work is performed by muscle action (ie eccentric contraction) to counteract external forces. Cavagna and Kaneko ${ }^{27}$ added absolute values of internal and external muscular work. In the present research we calculated mechanical work using both the Ralston and Lukin method (Figure 3a) and Winter's method (Figure 3b); it is evident that in both cases, quite the same ratio between RGO vs normal work was obtained.

The use of quadratic regression curves in Figure 1 entails the assumption of two constants which do not have a biological meaning, even although both curves are provided with good $F$ test statistics. We traced the curves only to indicate that (1) both in RGO subject and in normals, work increases in an exponential fashion with an increase in the speed of walking, (2) the rate of increase is much more pronounced in RGO than in normals, and (3) this difference in the rate of increase is statistically highly significant. It is improper to extrapolate beyond experimental data, but we can hypothetically assume that an RGO user walking at $1 \mathrm{~m} \mathrm{~s}^{-1}$ (ie near the economy speed for a normal subject) would have to do 14 times more work than normal people. On the basis of these results we can affirm that the high metabolic cost of RGO walking is primarily due to the great mechanical work needed to move the system.

Referring to a defective efficiency of muscle work as a possible explanation for the expensive cost of RGO walking, we must stress that in a previous study ${ }^{10}$ we obtained a mean energy cost of $560 \mathrm{~W}$ for arm cranking at $100 \mathrm{~W}$ of mechanical output in wheelchair athletes, which gives an efficiency of about $18 \%$ for work done by upper limb muscles. Thus a poor efficiency is not inherent to the work done by those muscles.

In RGO trunk and leg braces are combined in order to confer intrinsic stability to the body in standing, ie the subject is not requested to spend energy to maintain the upright posture. In forward progression with passive RGO upper limb, shoulder girdle, and upper trunk musculature are the only actuators that transform metabolic energy into positive mechanical work (or positive and negative in accordance with Winter). To make a step, the body is tilted laterally over the stance foot so that the swinging leg is cleared off the floor. The trunk is extended, extending in turn the standing hip and the Bowden cables, which interlink the two hip mechanisms and transmit the movement to the swinging hip, making it flex. Thus the forward step results. ${ }^{28}$

As represented in Figure 2, our data demonstrate that movements of the trunk entail simultaneous increments of kinetic and potential energy. The rigid leg compass gait also demands a consistent increase in kinetic energy to perform the swing movement. In our opinion the modality of energy transfer via trunk bending to the RGO actuator, implies a waste of energy, primarily because the leg movements entail great changes of both potential and kinetic energy. Besides, we supposed that only a minimal part of work done by the trunk could be transferred via the hip device to the legs. Therefore the greater work performed by paraplegic individuals compared with normal individuals is intrinsic to the mechanical characteristics of an RGO system.

In conclusion we share the judgement that Bowker et $a l^{28}$ manifested about the RGO device: although useful in restoring the normal range of reach in an environment designed for the able bodied, its high energy cost -along with the consequent slow mobility-limits its use to the indoor environment. To respond to the demand for real mobility, the mechanism for transmitting work from the upper body to the legs must be substantially changed, and/or energy must be found elsewhere from upper body musculature (external power or FES). 
The aim of the present research was to give some data that would be useful for future orthosis improvement. Nevertheless, two minimal suggestions for physiotherapists can be immediately pointed out: (1) good paraplegic training must be given before RGO use, not only directed toward muscular strength, but also toward good aerobic power, with particular regard to cardiovascular conditioning, and (2) diet must be well regulated in order to reduce body mass, and particularly trunk mass, reducing body fat to normal range according to sex and age.

\section{References}

1 Douglas R, Larson PF, D'Ambrosia R, McCall RE. The LSU reciprocating-gait orthosis. Orthopedics 1983; 6: 834-839.

2 Kantor C et al. Report on a conference on motor prostheses for workplace mobility of paraplegic patients in North America. Paraplegia 1993; 31: 439-456.

3 Nene AV, Patrick JH. Energy cost of paraplegic locomotion with the ORLAU parawalker. Paraplegia 1989; 27: 5-18.

4 Hirokawa et al. Energy consumption in paraplegic ambulation using the reciprocating gait orthosis and electric stimulation of the thigh muscles. Arch Phys Med Rehabil 1990; 71: 687-694.

5 Puricelli $\mathrm{R}$ et al. Il consumo energetico durante il cammino di pazienti paraplegici traumatici adulti. Eur Med Phys 1993; 29: 235-244.

6 Solomonow M, Baratta R, Hirokawa S, Rightor N. The RGO generation II: muscle stimulation powered orthosis as a practical walking system for thoracic paraplegics. Orthopedics 1989; 12: $1309-1315$.

7 Ferrarin M, Stallard J, Palmieri R, Pedotti A. Estimation of deformation in a walking orthosis for paraplegic patients. Clin Biomech 1993; 8: 255-261.

8 Jefferson RJ, Whittle MW. Performance of three walking orthoses for the paralysed: a case study using gait analysis. Prosthet Orthot Int 1990; 14: 103-110.

9 Lucia A, Fleck SJ, Gotshall RW, Kearney JT. Validity and reliability of the Cosmed K2 instrument. Int J Sports Med 1993; 14: $380-386$.

10 Marchetti $\mathbf{M}$ et al. Idoneita' allo Sport Agonistico per Atleti su Sedia a Ruote I Quaderni Centro Ricerche Clinica S. Lucia, 1992, Roma.

11 Zatziorsky V, Seluyanov V. The mass and inertia characteristics of the main segments of the human body. In: Matsui $\mathrm{H}$,
Kobayashi K (eds). Biomechanics VIII-B. Human Kinetics Publisher: Champaigne, Illinois, 1983, pp 1152-1159.

12 Sachs L. Applied Statistics. A Handbook of Techniques, 2nd edn. 1982, Springer Verlag, pp 433-442.

13 Paul JP. Concept in gait analysis. In: Berme N, Cappozzo A (eds). Biomechanics of Human Movement. Applications in Rehabilitation, Sports and Ergonomics. Bertec Co, 1990, pp 396-403.

14 Margaria R. Sulla fisiologia, e specialmente sul consumo energetico, della marcia e della corsa a varie velocita' ed inclinazioni del terreno. Atti Acc Naz Lincei 1938; 7: 299-368.

15 Huang CT, Kuhlemeier KV, Moore NB, Fine PR. Energy cost of ambulation in paraplegic patients using Craig-Scott braces. Arch Phys Med Rehabil 1979; 60: 595-600.

16 Clinkingbeard JR, Gersten JW, Hoehn D. Energy cost of ambulation in the traumatic paraplegic. Am J Phys Med 1964; 43: $157-165$.

17 Merkel KD, Miller NE, Westbrooke PR, Merrit JL. Energy expenditure of paraplegic patients standing and walking with two knee-ankle-foot orthoses. Arch Phys Med Rehabil 1984; 65: $121-124$.

18 Ralston HJ, Lukin L. Energy levels of human body segments during level walking. Ergonomics 1969; 12: 39-46.

19 Marchetti M, Cappozzo A, Figura F, Felici F. Race walking versus ambulation and running. In: Matsui $\mathrm{H}$, Kobayashi $\mathrm{K}$ (eds). Biomechanics VIII-B. Human Kinetics Publisher: Champaigne, Illinois, 1993, pp 669-675.

20 Winter DA. A new definition of mechanical work done in human movement. J Appl Physiol: Respirat Environ Exerc Physiol 1979; 46: 79-83.

21 Ralston HJ. Energy-speed relation and optimal speed during level walking. Int $Z$ angew Physiol 1958; 17: 277-283.

22 Cotes JE, Meade F. The energy expenditure and mechanical energy demand in walking. Ergonomics 1960; 3: 97-119.

23 Hoffman DM. Cardiorespiratory fitness and training in quadriplegics and tetraplegics. Sports Med 1986; 3: 312-330.

24 Shephard RJ. Sports medicine and the wheelchair athlete. Sports Med 1988; 4: 226-247.

25 Di Prampero PE. The energy cost of human locomotion on land and in water. Int J Sports Med 1986; 7: 55-72.

26 Cappozzo A, Leo T, Pedotti A. A general computing method of the analysis of human locomotion. Rapporti Istituto Automatica I Università di Roma and Centro Studi Sistemi Controllo e Calcolo Automatici CNR, 1973.

27 Cavagna GA, Kaneko M. Mechanical work and efficiency in level walking and running. $J$ Physiol 1977; 268: 467-481.

28 Bowker P, Messenger N, Ogilvie C, Rowley DI. Energetics of paraplegic walking. J Biomech Eng 1992; 14: 344-349. 